An Electric Scooter with Super-Capacitor Drive and

\title{
Regenerative Braking
}

Li Sun, Mohamed Awadallah, Lianhua Chi, and Nong Zhang

Univ, of Technology Sydney

CITATION: Sun, L,Awadallah, M, Chi L, and Zhang, N. "An Electric Scooter with Super-Capacitor Drive and

Regenerative Braking." SAE Technical Paper 2014-01-1878, 2014, do: 10.4271/2014-01-1878.

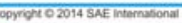

\section{Abstract}

This paper presents a smart electric scooter system consisting of a microprocessor based vehicle controller (integrating an

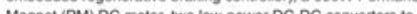
form a higher power DCDC convertes pack a motor controluer. a supercapacitor bank and a capacitor cell balancing sub. system.

During acceleration or forward motoring mode, the vehicle controlier sets the DC motor into motoring mode to further

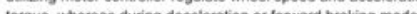
sets the DC motor int braking mode and further uning mase, regenerative braking controller regulate wheel speed and braking torque, as well as functions as a constant current (Whose reference value is adjustable via a potentiometer) generator to charge the supercapactor bank in a controllable fastion, hence not only successfully replacing frictional braking to certain degree, but also increasing the total energy efficien capactance of the soperoperitor conpared with other capcental

General structure of the smart system, control principle of the controllers, realizatoon of measurement plattorm, experimenta test setup as well as validation with results are all presented within this paper.

\section{Introduction}

Regenerative Braking has long been used in electric trains or trams, and nowadays, electric vehicles (EV) or hybrid electric vehicles (HEV), to save energy [1][2]. For the former, dynamic implementation, whereas for the latter, a battery pack is more suitable and normally is used to recover braking energy under partly due to the lower EMF(Electromotive Force) produced while motor is operating within lower rpm range, from which the back EMF produced by the motor alone is too low to charge back the high-voltage battery pack; on the other hand,

conventional electro-chemical battery cells are susceptible to heat toss undertigher coptent regulated under 3 C riting io ensure sately [3] Also, high seen by the battery is detrimental to battery lifecycle honce deteriorates its performance.

Supercapacitor seems to be a better option to address this issue, while maintaining many of the positive etectioc battery charactenstics. From inerature research

supercapacitors, seem to oftes an effective way to ruce penk battery currents, hence enhancing the battery life. Such feature discussed in the anticle [4] has intrigued the author developing and testing a small-scale drive system - a scooter capable of taking bi-directional power flow between a supercapacitor bank and $\mathrm{B} D \mathrm{C}$ motor.

Compared with a regenerative braking circuit described in [5]. new approach, in aids of modern power electronics and more bbust control, is described within this paper. Besides. uuantitative analysis and pertormance evaluation is carried out

\section{Component Sizing}

An electric scooter, as shown in Eigure 1, has been acquired

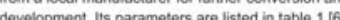




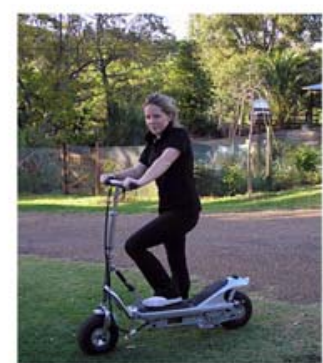

Figure 1

Tabie 1

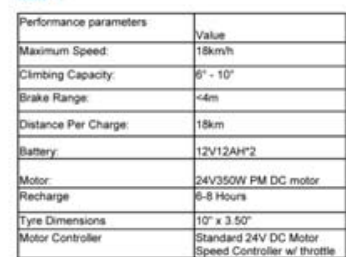

Supercapacitors

For space considerations, the choice was made at the time to use a bank consisting of six cells of 3000 Farad

Boostcapsolope supercapchor (each ated at 2.T. With Figure 2) for replacing the two 12V-bettery module listed in Table 1 for use of energy source. Relevant energy calculation is conducted in the following to rationalize this selection.

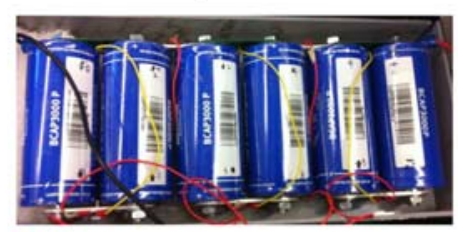

Finue 2
Considering the cut-off cell voltage is $1.5 \mathrm{~V}$, total usable electrical energy is:

$$
E=\frac{1}{2} C\left(V_{2}^{2}-V_{1}^{2}\right)
$$

where $V_{2}$ is the fully charged $D C$ voltage of the supercapacitor bank, for six cells, equals to $16.2 \mathrm{~V}$ and $\mathrm{V}_{\text {, its }}$ cut-olf voltage. for six colls to be $9 \mathrm{~V}$. The overail capaciance is reduced into coofarad due to the nature of senaly connected capacitor can be calculated from equation 1 a 45,360 , mich energy an approximate 150-second continuous ride at maximal outo power (300W) of the DC motor. This is good enough for a few continuous accelerations of travelling over a certain distance.

Note the cut-off voltage is constrained by the minimum input voltage $D C D C$ converter takes, which will be addressed in lollowing paragraphs.

Similarly during deceleration, the usable (excess) kinetic energy needed to be absorbed so as to stop the scoter

$$
E=\frac{1}{2} N\left(S_{i}^{z}-S_{i}^{z}\right)
$$

Where $M$ is the total mass of the scooter and driver, which is assumably weighed at 100kg: $\mathrm{S}_{2}$ is the initial speed and $\mathrm{S}$, is the end speed (Note ' $S$ ' is used here to avoid contusion against the annotation " $\mathrm{V}$ " usect

Let's assume the initial speed for a ride is at $25 \mathrm{~km} / \mathrm{hr}$, i.e. $6.94 \mathrm{~m} / \mathrm{s}$, and the end speed is $8 \mathrm{~km} / \mathrm{hr}$, i.e. $288 \mathrm{~m} / \mathrm{s}$. The overal kinetic energy therefore can be calculated by using equation. (2) at approximately $2000 \mathrm{~J}$. Considering only the rear wheel is providing all the braking power, as well as all the other losses in the system, at he first order of estimation, 1 the rogenerative braking controher is able to recover so\% of this 20005 traking $300 \mathrm{~W}$, which results in current approaching $20 \mathrm{~A}$ at $15 \mathrm{~V}$.

Note the end speed is constrained, once again, by the DC-DC converter since the motor back EMF wi drop under the minimum converter input threshold when its speed gets too low (in this case, 8km/hr)

\section{DC-DC Converter} market to choose a sulable DC-DC converter. The objective of the converter is to boost the variable $\mathrm{DC}$ voltage source of the supercapacitor bank up to $24 \mathrm{~V}$ hence forming a rigid high perers the bus powers the motor as 4 it was powered ongininally from the 
This is because the highest voltage the supercapacitor bank under $16.2 \mathrm{~V}$, is always lower than the $24 \mathrm{~V}$ converter DC bus output voltage.

Both conventional forward and flyback types of DC-DC converters have a maximal power rating at approximately

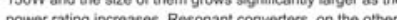
hower are capable of dealing with high powers on the other smaller size. The converter gets smaller mainly by increas their operating frequency to decrease the size of the power transtormer and output $L C$ or capacitive filter. The smaller hea sink can also be achieved due to the increased efficiency [i]. Two 150W DC-DC resonance converters (with output voltage regulated at 12V, input voltage varies from 9-36V, switching requen act way both tight packaging constraints and power rating is achieved simultaneousty

Note it is well worth to include a chapter to discuss how the converter efficiency affect the system, however due to the timing constraints a the phofoch was decided to conduct a

\section{Development of Vehicle Controller}

Up till this point, we have ascertained four major components from the sections described above including:

Carry-over components from the off-the-shelf electric sceoter

- 300W PM DC Motor,

- $24 \mathrm{~V}$ Motorispeed controller

Newireplacement components

- $6 \times 3000 \mathrm{~F}$ supercapacitor bank (replacing battery packs) - $2 \times$ DC-DC resonant converters

It then can be properly deduced, before discussing more details of the regenerative braking controlier, what function the venicie controler should be developed into, at a higher

The vehicle controller should be able to:

- Select the vehicle drive modes between acceleration and braking via a mechanical switch set by user.

- Interface and connect all four major components articulatod in the beginning of this section.

Integrate a sub-circuit to pertorm regeneratve braking

Whose currentbraking torque reference is adjustable

Have built-in measurement test points or terminals for
further analysis, data acquisition and/or troubleshooting
In 19. it is suggested with electric braking it is normal to (t) application for most systems fades. However this paper concentrates primarily on electrical braking itself, leaving auxiliary issues such as blending, salety and each corresponding mplementaton with lollowing papers.

Regenerative Braking Controller

It is intuitive and economical to embed the whole regenerative chematic diagram in Eigure 3 lilustrates its operation

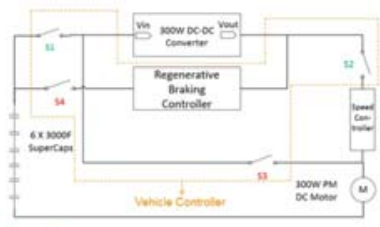

First of all it can be seen, that the vehicle controller consists of he Regenerative braking controller and four power switches

Secondly two altermative paths can be formed by utilizing and Figure 5 as well This wayd onders as shown in Figure needed to feed the power from source to load bi-directionally.

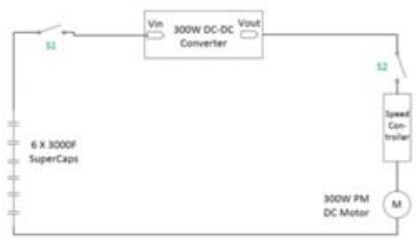

Figute 4

In forward motoring mode, S1 and S2 close witive S3 and S4 open, power is delivered from the supercapacitor bank to the in figure 4 


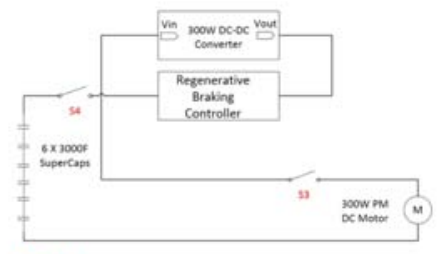

Figure 5.

In forward braking mode, S3 and S4 close while S1 and S2 open, power is delivered from the $\mathrm{DC}$ motor back to

supercapachor va hiecomener and nue

A current mirror sub-circuit design is utilized to regulate the

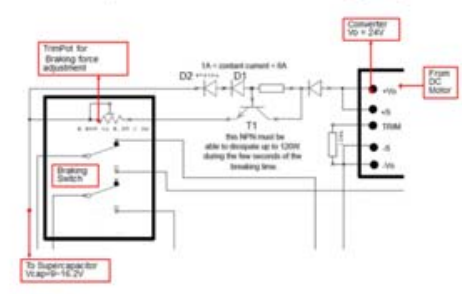

Figure 6.

The adjustable range of the output current this circuit regulates is the quotient of the voltage drop across the Schottiky diode

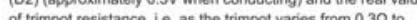
0.4p the of $0.04 \mathrm{R}$, the adjustment range
varying from $1 \mathrm{~A}$ up to $7.5 \mathrm{~A}$.

Note moderate amount of power loss occurs over the NPN power transistor $\mathrm{T} 1$ due to the nature of linear rogulating mechanism. This issue has been alleviated in practice by stacking up one more power NPN transistor in parallel so that the neat each ransistor takes is haved. A proper hear simk is Draking and lor low supercapacitor terminal voltege within a couple of seconds.
Drive Mode Selection and Control of 4 Power Switches via Microprocessor

The other important part of the vehicle controller is to ensure,

The other imporant part or the previous section) are switched in the right sequence and combination given the corresponding inpuls. This is achieved by utilizing an 8-bit microprocessor called PIC16F88.

The flow chart of the main program has been illustrated in Eligure Z, which somewhat describes the operational principile

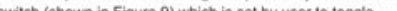
vehiche drive mace such input has been stabilized affer debouncing, a variable called "Brake flag" is set and the microprocessor can then decide states of its multiple outpuls to further regulate the sequence and combination of all four power switches. $20 \mathrm{~ms}$ deadtime has been set to svoid all switches being turned on in

The magnitude of braking torque can be varied on-the-fly as explained in the previous sector.

The microprocessor is assembled inside the regenerative braking controller boarc.

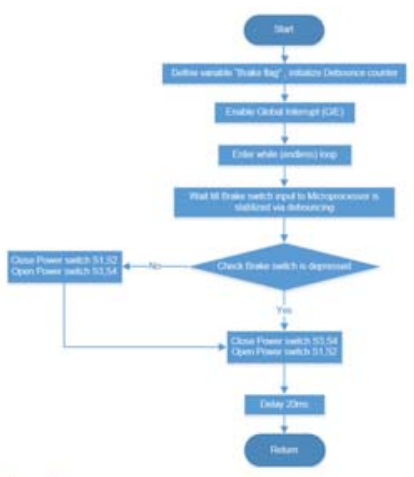

Figure?

Up to this point both hardware and software setup has been described. Figure 8 shows a picture including all major 


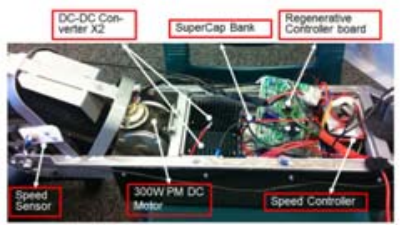

Figure B.

Measurement and Data Acquisition

Last important aspect of the system is for measurement an evaluation. To do this a set or Data Acquisition (DAQ) devine callod USB-6009s irom Nabonal instrument (N) has been outputs.

A custom-made speed sensor (also is shown in Figure 8) has been developed using Hall-eflect element and 12 magnets affixed around the wheel rim. The Hall-effect sensor therefore generates 12 taling edges per wheet revolution with is senso output connected to the ppFo terminal of the DAQ device Working as a coumen. Combing win nocessary timing signals

Fiqure 9. shows the physical layout of the measurement plattorm. Other than the speed signal, braking current supercapacitor termina voltage and DC motor back EMF are all sensed within the Regenerative controller board and then

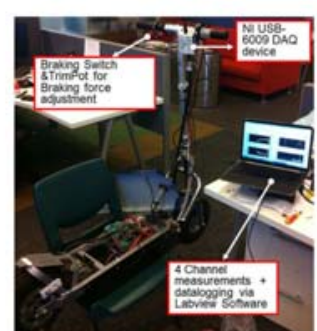

Figure 9

A graphical program to capture and log three analog channels of signal smultaneously using Labview sottware has been shown in Figure 10 for reference.

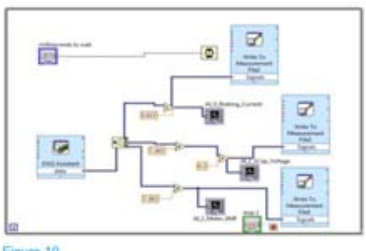

Experiment and Discussion

To observe energy flowing back from the scooter motor to

supercapacitor, the motor has to be diviven firstly to a

Sidfiently high speed before eloctrical braking is applied

Besides the braking processs is better to be prolonged for a few

supercepecior diseherging can be observed during the

acceleration phase.

Therefore experiment has to be conducted on a ramp having a slight downhili grade with a moderately large inertia i.e. one scooter (weighs approximately $25 \mathrm{~kg}$ ) over approximately 20 seconds.

Note although the downhill ramp will help moving the scooter down the ramp. the scooter will still need to be powered by tho motor to achieve an acceptable level of acceleration, partly due to the large inertia the driver exerts, partly the rolling resistance

Scooter Force Balancing Analysis

Firstly a scooter force balancing analysis has been undertake to better understand the role of the etoctrical braking force amongst omer imponant forces (as shown in favire i11. As the

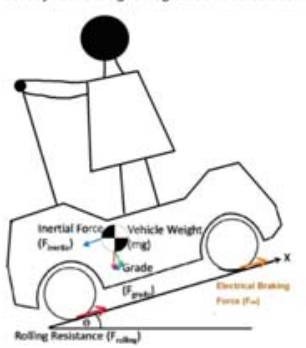

Figure 1 
The Inertial Force $(F)$ as shown in Figure 11 can be calculated $F_{t}=M g \sin \theta$

where $\theta$ represents the inclined angle of the ramp. The equivalent force representing rolling resistance can be calculated by:

$$
F_{r}=M g f, \cos \theta
$$

Where $f$, is the rolling resistance coefficient, which is a function of tire material, tire structure, tire temperature, tire inflaton pressure, tread geomety, road roughness, road material, an

In vehicle performance calculation, it is sufficient to conside For the most common range of inflation pressure, the following equation can be used on a concrete road [i]:

$$
f_{r}=0.01\left(1+\frac{S}{160}\right)
$$

where $S$ is the scooter speed in $\mathrm{kmmh}$. This equation presicts the values of $t$, with accoptable accuracy for speeds up to the values of
$128 \mathrm{~km} / \mathrm{hr}$.

The force balancing model will be used and discussed more in details when a known load torque can be applied to the system on a stationery lest rig set up in future papers.

\section{Scooter Experimental Test Setup}

A downhill ramp, located in a quiet street block close to the city campus or the UTS universily, has been deemed sulable tor is shown in Eigure 12 together with the instrumentation dese

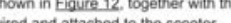

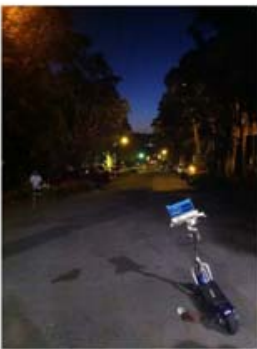

The gradient of the ramp has been measured approximately a protractor, the total mass of the driver and the scooter is approximately weighed at $100 \mathrm{~kg}$, and Cerage braking speed is expected at $12 \mathrm{~km} / \mathrm{hr}$.

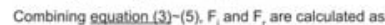

- $F \mathrm{i}=51.3 \mathrm{~N}$

$\mathrm{Fr}=10.7 \mathrm{~N}$

Two types of braking conditions are evaluated in the next

section with usefur scooter variables measured and they are:

- Fast (Emergency) braking

- Slow (Continuous) braking

Fast (Emergency) Braking

The trimpot setting braking currenttorque reference has been

dojusted to its maximum value to aim attempting an emergency

13 -16. Note strong electromagnetic noise is ptesent under

medium and high load conditions. At this stage the author uses

dashed lines to indicate averaged results in areas the noise

occurs.

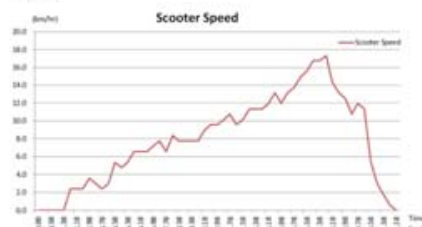

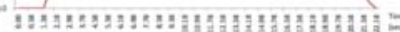

Fique 13.

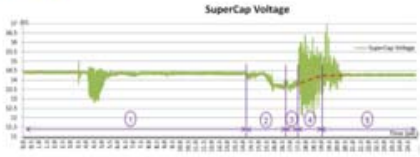

Figure 14.

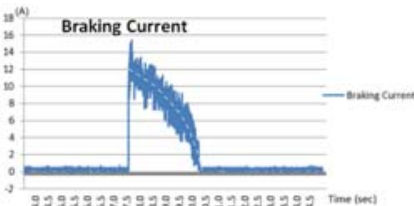

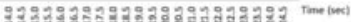




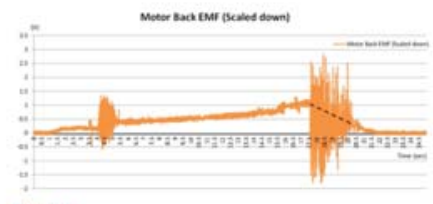

Figue 16

Five phases are present throughout the event as indicated in Figure 14 and they are:

- Phase 1 (from 0-14.2s) : light acceleration in aid of motor to speed up the scooter to around $12 \mathrm{~km} / \mathrm{hr}$

Phase 2 (from 14.28-16.7s): further heavier accoleration in aid of motor to around $18 \mathrm{~km} / \mathrm{hr}$

Phase 3 (from 16.75-17.5s): coasting with both motor and brake turned off, scooter speed increased very slightly due to its inertia force

Phase 4 (from 17.5s-19s): Brake switch is depressed, the scooter goes into electrical braking mode by lowering its spocd ha

Phase 5 (tom 19 sertd:

Phase 5 (trom

around one second (hence the scooter is lightly accelerated) before mechanical braking is applied to further brake the scooter down to standstit

Amongst all the phases, a few observations can be made:

- In phase 1 and 2, the supercapacitor bank undergoes discharging process, its terminal voltage is therefore
decreased from $14.48 \mathrm{~V}$ (initial value) down to $14.20 \mathrm{~V}$ phase 1) and from $14.20 \mathrm{~V}$ down to $13.60 \mathrm{~V}$ (in phase 2). The terminal voltage drop of the supercapacitor is reasonably proportional to the magnitude of acceleration.

In phase 3, the terminal voltage of the supercapacitor goes up from $13.60 \mathrm{~V}$ to $13.75 \mathrm{~V}$. This is because the supercapactor regains the voltage drop across its interna resistance when irs put back to open circuit condition.

The terminal voltage of the supercapacitor goes up from $13.8 \mathrm{~V}$ to approximately $14.2 \mathrm{~V}$ in phase 4 for approximately 1.5 second. The average current (1 system input energy $E_{\text {n }}$ consisting both kinetic energy $E_{\text {. }}$ and potential energy $E_{v}$ has ther electrical energy, altogether they can be calculated by:

$$
E_{m}=E_{p}+E_{i}=M g S T \sin \theta+\frac{1}{2} M\left(S_{2}^{2}-S_{i}^{2}\right)
$$

where $S_{2}$ and $S$, is respectively the end speed and initial speed within phase 4 and $S$, the average scooter speed. T
Knowing $T=1.5$ second, $M=100 \mathrm{~kg}$ and $\theta=3^{*}$, also
substituting into equation (6) with $S 2=17.4 \mathrm{~km} / \mathrm{hr}$, $S 1=12.2 \mathrm{~km} / \mathrm{hr}$ and $\mathrm{S}=14.8 \mathrm{~km} / \mathrm{hr}$ and converting them in standard metric unit we get

$$
E_{p t}=E_{p}+E_{t}=301.7+593.7=895.4 \mathrm{~J}
$$

The system output energy $\left(\mathrm{E}_{\text {oud }}\right)$, in our case is the energy recuperated back into the supercapacitor bank $\left(E_{i c e s}\right)$. The viefall conversion

$E f f=E_{\alpha} / E_{w}=V_{m p} \cdot I_{\text {meq }} \cdot T / E_{w}$

where Vscap and Iscap are the average terminal voltage tectral braking Taping Vscap as $14 \mathrm{~V}$, Iscap as peAiod substituting them into equation (8) we get:

$E f f=E_{\text {estr }} / E_{m i t}=210 \mathrm{~J} / 895.4 J=24.5 \%$

- Motor Back EMF is shown in Eligure 17, whose magnitude (scaled down due to measurement limit) is inearly proportional to the motorfiscooter speed, which agrees well with theory over PM DC motor:[11]

\section{Slow (Continuous) Braking}

For the second part of testing, the trimpot setting the braking currenthlorque reference has been adjusted to a medium value prolong the electrical braking period before the scooter speed drops below the regeneration threshold. The expectation is by varying the braking current reference, which from PM DC motor theory, bethaves somehow inearty proportionat to the the scooter atong the ramp is cancelled out (reter in Figure 11 . hence longer electrical braking period can be obtained with important system variables measured out

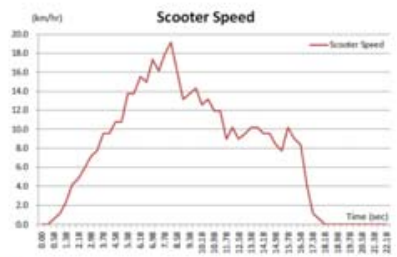
Figure 17.

Elgure $17-20$ illustrate measurement results after conducting a few trials to calibrate the position of the trimpot

There are once again, five major phases in the ride as indicated in Figure 18 But they are moderately different to hose of the previous test setup: 
Phase 1 (from 0-6.5s) : continuously heavy acceleration in aid of motor to specod up in: sc brake turned off, scooter speed reaches its top value at around $19 \mathrm{~km} / \mathrm{hr}$

Phase 3 (from 8.1s-12s): Brake switch is depressed, the speed to around $10 \mathrm{~km} / \mathrm{hr}$, at which speed the back EMF generated by the motor is still sufficiently high enough to keep powering the converter

Phase 4 (from 12s-16.2s): the scooter goes into constant

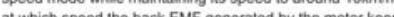
powering the converter to fharge the supercepactor heeps by exerting electrical braking torque

Phase 5 (from 16.25-end): mechanical braking is apolied to further brake the scooter down to standstill

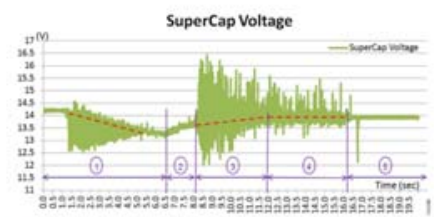
Figure 18

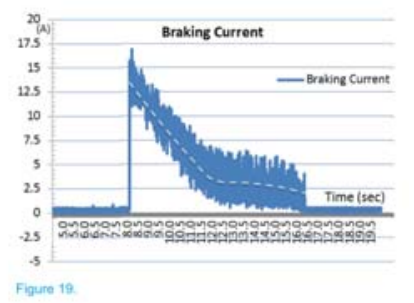

Figure 19

Similarly to the previous case, a fow observations can be made:

- In phase 1, the supercapacitor bank undergoes a discharging process, its terminal vollage is therefore Compared with phase 1 and 2 in the previous case slope of voltage drop is much steeper, corresponding to much heavier acceleration, which is reflectod in Figure 17 In phase 2, the terminal voltage of the supercapacitor recovers for the same reason as that of the previous case The terminal voltage of the supercapacitor goes up from $13.5 \mathrm{~V}$ to approximately $13.9 \mathrm{~V}$ in phase 3 and phase 4 for around 8 second. The braking current gradually decreases in four seconds from around 13A down to $3 \mathrm{~A}$ and then is pise prest constant for another 4 seconds. Due to the and the average current $(1$, in for these two phases can bo estimated around 5.5A (from Figure 19).

Knowing $T=8$ second, $M=100 \mathrm{~kg}$ and $\theta=3^{\circ}$, also atter convert ing S2 $=10 \mathrm{~km} / \mathrm{hr}, \mathrm{S} 1=19 \mathrm{~km} / \mathrm{hr}$ and $\mathrm{S}=12.25 \mathrm{~km} / \mathrm{hr}$ (also is obtained using the same approximation technique deriving the average current (hape or the supercapacioe of them into cauation (6) we get system inpu energy $E$

$E_{u t}=E_{p}+E_{\mathrm{t}}=1333.5+1006=2339.5 \mathrm{~J}$

Substituting $V_{\text {voe }}=13.7 \mathrm{~V}, \mathrm{I}_{2}=5.5 \mathrm{~A}$ and $\mathrm{T}=8$ second, into Equation (7) we get

$E f f=E_{\text {of }} / E_{\text {i }}=602.8 \mathrm{~J} / 2339.5 \mathrm{~J}=25.7 \%$

- Motor Back EMF for this test setup is shown in Eligure 20.

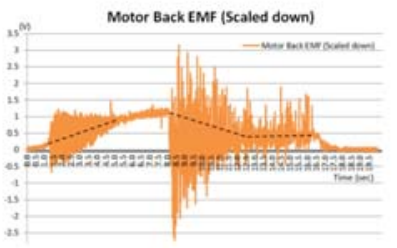

Figure 20.

Discussion

Comparing the results of the two test setup, a few findings are:

- Slow continuous braking seems to have a slightly higher

(by $1.2 \%$ ) energy conversion efficiency than fast emergency braking, also it is clear that more energy has been

recovered in the slow braking test as well.

In steady state, the average current for the fast braking case is measured higher than the slow traking case whose braking current later converged to the set value at constant crising speed. This correlates well the ilnear relationship Cloctivenes of current reguaton in PM DC mor control in both motoring mose and braking mode.

The energy conversion efficiency may be improved by lopologies, developing switching-mode braking regulator. orland adding regenerative braking to the front wheel of the scooter. 
